\title{
DETECTION OF MYCOBACTERIUM AVIUM IN PET BIRDS
}

\author{
Silvia Neri Godoy ${ }^{1 *}$; Sidnei Miyoshi Sakamoto² Cátia Dejuste de Paula $^{3}$; José Luiz Catão-Dias³ \\ Eliana Reiko Matushima ${ }^{3}$
}

\begin{abstract}
${ }^{1}$ Instituto Chico Mendes de Conservação da Biodiversidade, Brasília, DF, Brasil; ${ }^{2}$ Departamento de Ciências Animais, Escola Superior de Agricultura de Mossoró, Mossoró, RN, Brasil; ${ }^{3}$ Departamento de Patologia, Faculdade de Medicina Veterinária e Zootecnia, Universidade de São Paulo, São Paulo, SP, Brasil
\end{abstract}

Submitted: June 18, 2008; Returned to authors for corrections: July 23, 2008; Approved: March 31, 2009.

\section{SHORT COMMUNICATION}

\begin{abstract}
The present study is a report on the presence of Mycobacterium avium in four birds of the psittaciform order kept as pets. Anatomopathological diagnosis showed lesions suggestive of the agent and presence of alcohol-acid resistant bacilli (AARB) shown by the Ziehl-Neelsen staining. The identification of Mycobacterium avium was performed by means of PRA(PCR Restriction Analysis). DNA was directly extracted from tissue of the lesions and blocked in paraffin. The role of this agent in pet bird infection is discussed, as well as its zoonotic potential.
\end{abstract}

Key words: Mycobacterium avium; Psittacines; Pathology; Birds

\section{DETECTION OF MYCOBACTERIUM AVIUM IN PET BIRDS}

The genus Mycobacterium involves a group of ubiquitous organisms with more than 80 species. Each of them may be classified as saprophytic, potentially pathogenic for men and other animals, or strictly pathogenic. At least 25 species have been associated with the disease in humans (7). Although Mycobacterium avium is commonly found in birds of the most different families, there are reports involving $M$. tuberculosis, $M$. bovis, M. intracelullare, $M$. genavense $(1,4,8)$ and $M$. Columbae (12) and psittacides.

For a long time, Mycobacterium avium and M. intracelullare were considered to be the same agent, but nowadays they are classified as different species (4). However, it is very difficult to differentiate them morphologically, biochemically and serologically, and they are normally grouped in a complex called Mycobacterium avium/Mycobacterium intracelullare (MAC) $(4,5,8)$. MAC is composed of slow-growing bacteria, serologically classified in 28 serovars. Serovars 1 to 6,8 to 11 and 21 were attributed to bacteria in the $M$. avium species (M. avium avium, M. avium silvaticum, $M$. avium paratuberculosis and $M$. avium hominissuis) and serovars 7, 12 to 20 and 25 to bacteria in the M. intracellulare species. Serovars 22 to 28 (except serovar 25) were considered to be heterogeneous and could not be attributed to any of the two species (4).

Humans, non-human primates, ruminants, swine and marsupials have shown to be sensitive to infections by MAC (8). In humans, it has been associated to sporadic cases of pulmonary disease $\mathrm{e}^{9}$ and lymphadenitis, mainly in children and immunosuppressed individuals $(5,8)$. With the AIDS pandemics, infections by $M$. avium in contaminated patients emerged, mainly in underdeveloped countries.

This report shows the presence of Mycobacterium avium in four birds that took part in a study involving 130 psittacides, and which died in zoos and households.

Birds were submitted to post-mortem examination. Fragments of all organs were collected, fixed in formaldehyde $10 \%$, included in paraffin and stained by hematoxilin-eosin and Ziehl-Neelsen.

*Corresponding Author. Mailing address: Instituto Chico Mendes de Conservação da Biodiversidade, ICMBio, Rua Prof ${ }^{a}$. Elizabete Rolim, 116, Previdência, São Paulo, SP, Brasil. Cep 05514-080. Phone: 5561 9826-0868. E-mail: silng@uol.com.br 
During the post-mortem examination, blood samples were collected by cardiac puncture with disposable syringes and needles. Samples were kept in hemoculture medium, incubated at $37^{\circ} \mathrm{C}$ for 18 to 24 hours; aliquots were plates in blood agar and incubated at $37^{\circ} \mathrm{C}$ for 18 to 24 hours in aerophilic and microaerophilic conditions. For the study of fungi, samples were cultured in tubes containing Sabouraud agar added of chloranfenicol, and incubated at room temperature.

Histological sections were submitted to extraction of genetic material for the polimerase chain reaction (PCR). In order to prevent cross-contamination between samples, the laboratory bench, pliers and scisors used were treated with $\mathrm{HCl} 0.1 \mathrm{M}$ for 2 minutes and a new blade was used in every sample. Samples were deparaffinized, centrifuged, incubated, washed and purified for DNA extraction and the PCR for mycobacterium study. This study was did according to the protocol described by SAITO et al. (10).

For the final identification of the mycobacterium species, profiles of the bands produced by digestion of the PCR products, also called PRA (PCR Restriction Analysis), were compared with the classification algorithm proposed by TELENTI et al. (11), whose corrected and updated version is available online at the PRA site (http://www.chuv.ch). The PRA method presents a great discriminatory power in species belonging to MAC, enabling the differentiation between $M$. avium and $M$. intracellulare, as well as other mycobacteria.

An anatomopathological study with 130 psittacides from zoos, private breeding farms and households showed the presence of Mycobacterium avium in four animals, two Australian parakeets (Melopsittacus undulatus) and two bluefronted parrots (Amazona aestiva). The former came from the same facility and the latter from two different sites, being kept as pets in households.

Clinical signs observed varied between the four birds, and three of them present unspecific signs such as prostration, ruffled feather and hyporexia. One of them presented digestive signs, such as diarrhea and hyporexia.

The two Australian parakeets died due to the infection by M. avium. One of the blue-fronted parrots died during a surgical procedure to remove the increased volume in the cervical region, and the other was euthanized due to the suspected disease and its general status.

The anatomopathological study of these animals showed different findings. One of the parakeets presented severe deposition of adipose tissue in the subcutaneous tissue, hepatomegaly and a large mass of intracavitary fat involving the intestines. Histopathological examination using ZiehlNeelsen staining showed the presence of multiple foci of alcohol-acid resistant bacilli (AARB) in liver, spleen, intestines and in the fat mass. The other animal of the same species presented severe atrophy of the chest muscles and hepatomegaly associated to several yellowish foci. In the microscopic examination, the presence of AARB was also observed in liver and spleen.

In one of the blue-fronted parrots, an extensive granulomatous mass was adhered to the mucous membrane of the cervical esophagus, totally occluding the lumen of the organ and connecting superficially with tracheal rings. In the histopathological examination, AARB colonies associated with extensive tissue necrosis and granulocytic inflammatory infiltrate were seen. The other animal presented multiple subcutaneous nodules in the cranium region, filled with caseous material and the presence of AARB, besides discrete granulomas in small foci in the lungs.

Microbiological examination of cardiac blood was negative in the four animals, and PRA reaction of the paraffined material showed the presence of Mycobacterium avium in the four birds studied.

The two species affected by Mycobacterium avium in the present study, Melopsittacus undulatus and Amazona aestiva are reported in specialized literature as being highly sensitive to the infection (8). In Brazil, they are among the most common pet birds.

Infection by M. avium mainly occurs by means of ingestion of the agent. However, it may occur after the inhalation of aerosols of contaminated feces $(2,4,8,12)$ or by arthropod transmission (5). When the agent is ingested, avian mycobacteriosis evolves mainly with the colonization of the intestinal wall $(4,5,8)$ and then the liver, with subsequent dispersion to other organs, such as the bone marrow, air sacs, spleen, skin, gonads and, sporadically, lung and pancreas. The lungs may also be infected when the agent is inhaled $(5,8)$. In psittacides, parrots in the genus Amazona and Australian parakeets are particularly sensitive to the infection (8).

Clinical signs of avian mycobacteriosis vary according to the organs affected. Acute form may lead to sudden death. However, most of the times, signs are related to chronic, debilitating disease and include weight loss, depression, diarrhea, polyuria and unsuccessful conventional antibiotic therapy $(3,4,6,8)$. Poor feathering, abdominal distention, claudication and presence of masses in subcutaneous and conjunctival tissue may also be observed. Dyspnea may be observed in animals showing pulmonary involvement (4). Adult birds generally develop the chronic, debilitating form of the disease, and immature individuals, the subclinical form $(3,5)$.

Three kinds of lesions may be seen in the birds: the classic lesion with tubercles in various organs, paratuberculosis with typical lesions in the intestinal tract, and the atypical form, without characteristic lesions, which is difficult to be recognized $(2,3,4,5)$.

The pathogeny of the disease varies according to the bird species infected and the serovar involved. The presence of small nodules in the intestinal wall, liver, spleen and bone marrow is characteristic of the infection by M. avium. In psittacides, 
most common lesions are granulomas in liver and spleen, which may also be observed in lungs and gastrointestinal tract. Tubercles in the skin are rare, but they may be present as nodules of different sizes, full of fibrinous yellowish material $(3,4,5,12)$. Dermatitis may occur in combination with other necrotic-ulcerative lesion in the tongue, perinasal and periorbital regions (4).

In the post-mortem examination, hepatomegaly, esplenomegaly and thickening of the duodenum wall may be observed. Histologically, nodules in the organs are characterized by a large number of epithelioid cells, occasionally giant cells and heterophyls $(3,5,6,8)$. Nodules frequently present a central necrosis area, which may be calcified in chronic cases. In psittacides, there is a tendency for diffuse histiocytosis (8). $M$. avium generally induces proliferation of macrophages and spleen reticular cells, and lymphoid depletion $(3,5,6)$.

Clinical signs and pathological findings observed in the birds of this study were highly variable. However, all of them are in accordance with those findings reported in specialized literature $(3,4,5,6,8)$. The Australian parakeet presented severe obesity, a large accumulation of adipose tissue in subcutaneous tissue, abdominal distension and strong dyspnea before death. In the anatomopathological study, it showed the disseminated for of the disease, the most classical one, probably determined by ingestion of the agent. The other animal of the same species presented progressive loss of weight, diarrhea and death, and after the anatomopathological study, it was shown that the classical form of the disease also affected this bird. One of the blue-fronted parrots presented difficulty in swallowing, prostration and increased volume in the cervical esophagus region. It died during a surgical procedure. After post-mortem examination, it was considered to be one more classical case of mycobacteriosis in the digestive system. The blue-fronted parrot presented several nodules of different sizes, located all over the skin of the cranium, and was euthanized due to the progression of the disease and the suspicion of mycobacteriosis. This animal showed the dermal form of the disease, considered to be rare in specialized literature $(3,4,5,6,12)$.

Although macro and microscopic findings in animals that presented mycobacteriosis do not confirm the presence of Mycobacterium sp, tissue sections stained by Ziehl-Neelsen show indications of infection. Definitive diagnosis, however, can only be reached with the isolation or detection of the agent in suspect samples. PRA has fundamental importance in definitive diagnosis of Mycobacterium sp, as well as in the identification of the species involved, as occurred in the present study, with the identification of Mycobacterium avium.

Despite the fact that many infected animals do not present the clinical form of the disease, they may eliminate the agent $(2,4,5)$. The zoonotic potential of Mycobacterium avium is small in healthy individuals, but risk increases considerably in children, elderly and immunosupressed individuals, who are more sensitive to the colonization by the agent and the effects of infection $(5,8)$.

Suspicion of mycobacteriosis occurs when structures similar to tumors recidivate after excision (5). Presumptive diagnosis is performed by demonstration of the agent in feces or histopathological examination using Ziehl-Neelsen staining for the study of alcohol-acid resistant bacilli (AARB). However, the determination of the species of the agent involved in only obtained after culture, with later phenotypic and biochemical characterization, or by means of DNA techniques (5). Tuberculin testing using the intradermic junction of the cloaca may aid diagnosis (1). Infected animals should be euthanized.

All birds in the present study were kept in places where they had direct contact with free birds, more specifically rock doves and plain-breasted ground doves. These animals may have been the primary infection source of the birds studied here.

There are many pet birds in households in Brazil. However, diagnoses of agents that infect these animals are not common. This shows the risk to both human and animal health in keeping these birds as pets in places were resources are scarce.

\section{ACKNOWLEDGMENTS}

To the Fundação de Amparo à Pesquisa (FAPESP) for financial support.

\section{RESUMO}

\section{Detecção de Mycobacterium avium em aves de companhia}

Este estudo relata a presença de Mycobacterium avium em quatro aves da ordem Psitaciformes, mantidos como animais de estimação. O exame anatomopatológico revelou a presença de bacilos álcool ácido resistentes na coloração de Ziehl-Neelsen, e o diagnostico definitivo foi feito pelo método PRA (PCR Restriction Analysis) a partir de tecidos emblocados em parafina. Este estudo visa alertar o possível potencial zoonótico deste agente em aves mantidas domiciliadas.

Palavras-chave: Mycobacterium avium; Psitacídeos, Patologia, Aves

\section{REFERENCES}

1. Burr, E.W. (1987). Companion Bird Medicine. Iowa State University Press, Ames, 247p.

2. Carpenter, J.W.; Gentz, E.J. (1997). Zoonotic Diseases of Avian Origin. In: Altaman, R.B. (ed). Avian Medicine and Surgery. W.B.Saunders Company, Philadelphia, USA, p.350-363.

3. Cubas, Z.S.; Godoy, S.N. (2005). Medicina y Patología de aves de compania. In: Aguilar, R.; Hermandez-Divers, S.M.; HermandezDivers, S.J.(eds). Atlas de Medicina, Terapéutica y Patologia de 
Godoy, S.N. et al.

Animales Exóticos. Inter-Médica, Buenos Aires, Argentina, p. 213262.

4. Dorrestein, G.M. (1997). Bacteriology. In: Altman, R.B. (ed). Avian Medicine and Surgery. W.B.Saunders Company, Philadelphia, USA, p. $255-280$.

5. Gerlach, H. (1994). Bacteria. In: Harrison, G.J.; Harrison, L.R.; Ritchie, B.W. (eds). Avian Medicine: Principles and Application. Wingers Publishing, Lake Worth, USA, p. 949-983.

6. Godoy, S.N. (2001). Patologia Comparada de Psitacídeos Mantidos em Cativeiro no Estado de São Paulo. São Paulo, Brasil, 214p. (M.Sc Dissertation. Faculdade de Medicina Veterinária e Zootecnia. USP).

7. Goyal, M.; Young, D. (1998). Molecular approaches in Mycobacterium tuberculosis and other infections caused by Mycobacterium species. In: Woodford, N.; Johnson, A. P. (eds). Methods in Molecular Medicine - Books Series v.15. Humana Press, New Jersey, USA, p.157-190.
8. Heyden, N.V.D. (1996). Mycobacteriosis. In: Rosskopf, W.J.; Woerpel, R.W. (eds). Diseases of Cage and Aviary Birds. Willians \& Wilkins, Baltimore, USA, p. 568-571.

9. Inderlied, C.B.; Kemper, C.A.; Bermudez, L.E.M. (1993). The Mycobacterium avium complex. Clin. Microbiol. Rev. 6 (3), 266-310.

10. Saito, H.; Tomioka, H.; Sato, K.; Tasaka, H.; Dawson, D. J. (1990). Identification of various serovar strains of Mycobacterium avium complex by using DNA probes specific for Mycobacterium avium and Mycobacterium intracellulare. J. Clin. Microbiol. 28 (8), 1694-1697.

11. Telenti, A.; Marchesi, F.; Balz, M.; Bally, F.; Böttger, E.C.; Bodmer, T. (1993). Rapid identification of Mycobacteria to the species level by polymerase chain reaction and restriction enzyme analysis. $J$. Clin. Microbiol. 31 (2), 175-178.

12. Zwart, P. (2000). Bacterial Diseases. In: Samour, J. (ed) Avian Medicine. Harcourt Publishers, London, England, p. 252-264. 